\title{
Uncommon variants of left circumflex coronary artery (LCX): evaluation with 256-slice dual source CT coronary angiography
}

\author{
Harmeet Kaur Rissam, ${ }^{1}$ Lalit Garg, ${ }^{2}$ Umesh Kumar Mittal, ${ }^{1}$ Satbir Singh ${ }^{3}$
}

${ }^{1} \mathrm{G}$ B Pant Hospital, New Delhi, India

${ }^{2}$ Department of

Radiodiagnosis, G B Pant Hospital, New Delhi, India

${ }^{3}$ Department of Radiology, G B

Pant Hospital, New Delhi, India

Correspondence to Dr Umesh Kumar Mittal, dr.umeshmittal@yahoo.co.in

Accepted 17 April 2015

\section{DESCRIPTION}

We report two cases of rare left circumflex artery (LCX) anomalies: one case of absent LCX with super-dominant right coronary artery (RCA) and another of anomalous origin of LCX from right coronary sinus.

Case 1: A 48-year-old woman presented with exertional dyspnoea. Echocardiography was normal. CT coronary angiography (on 256-slice CT scanner) revealed absent LCX in the left atrioventricular groove. The RCA was prominent and posterolateral branch was supplying the posterior wall of left ventricle. LCX territory was supplied by the small branches from diagonal arteries of left anterior descending artery (figures 1 and 2).

Case 2: A 58-year-old man presented with atypical chest pain. Echocardiography was normal. CT angiography revealed anomalous origin of LCX from the right coronary sinus, adjacent to the origin of RCA (type II variant). The LCX was retroaortic in course, traversing between the aortic root and left atrium. No compression or luminal narrowing was seen (figures 3 and 4).

Congenital absence of LCX is a very rare anomaly with incidence of $0.003 \%$ in patients undergoing coronary angiography. CT coronary angiography is advantageous over catheter angiography in differentiating between congenital absence and complete obstruction. It also helps in delineating the course of the vessel in relation to the surrounding cardiac chambers. These patients may be symptomatic due to a steal phenomenon. ${ }^{1}$

Anomalous origin of LCX from right coronary sinus is the most common congenital variant with prevalence of $0.18-0.67 \%$. These patients may develop coronary symptoms due to kinking/compression in their retroaortic course (malignant course). ${ }^{2}$
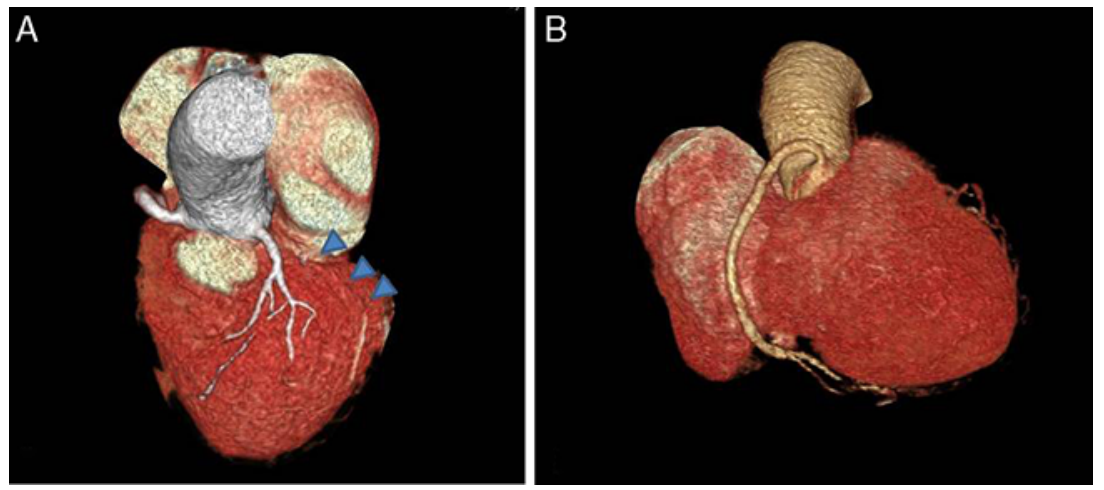

Figure $1 \mathrm{CT}$ angiography volume-rendering technique images showing absent left circumflex artery in the left atrioventricular groove (arrowheads in A) and dilated right coronary artery (B).
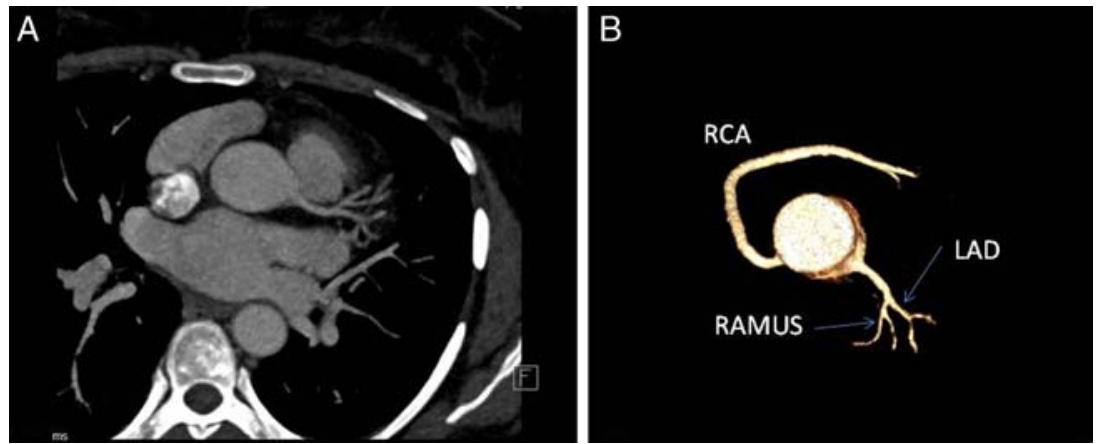

Figure 2 Axial MIP (A) and VRT (B) images showing division of left main coronary artery into LAD and Ramus intermedius with absent LCX (LAD, left anterior descending; LCX, left circumflex artery; MIP, maximum intensity projection; RCA, right coronary artery; VRT, volume-rendering technique). 
Figure 3 VRT images showing anomalous origin of $L C X$ from right coronary sinus (arrows in B) with retroaortic course (arrowheads in $A$; LCX, left circumflex artery; RCA, right coronary artery; VRT, volume-rendering technique).
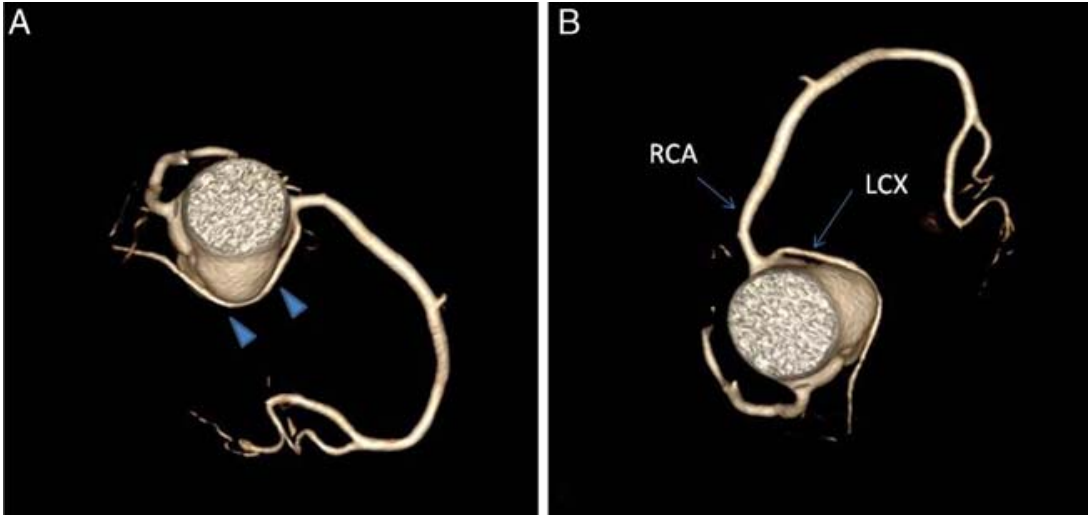

Figure 4 MIIP (A) and VRT(B) images showing $\mathrm{LCX}$ coursing between $A o$ and $\mathrm{LA}$ (Ao, aorta; $\mathrm{CL}$, cycle length; LA, left atrium; MIP, maximum intensity projection; VRT, volumerendering technique).
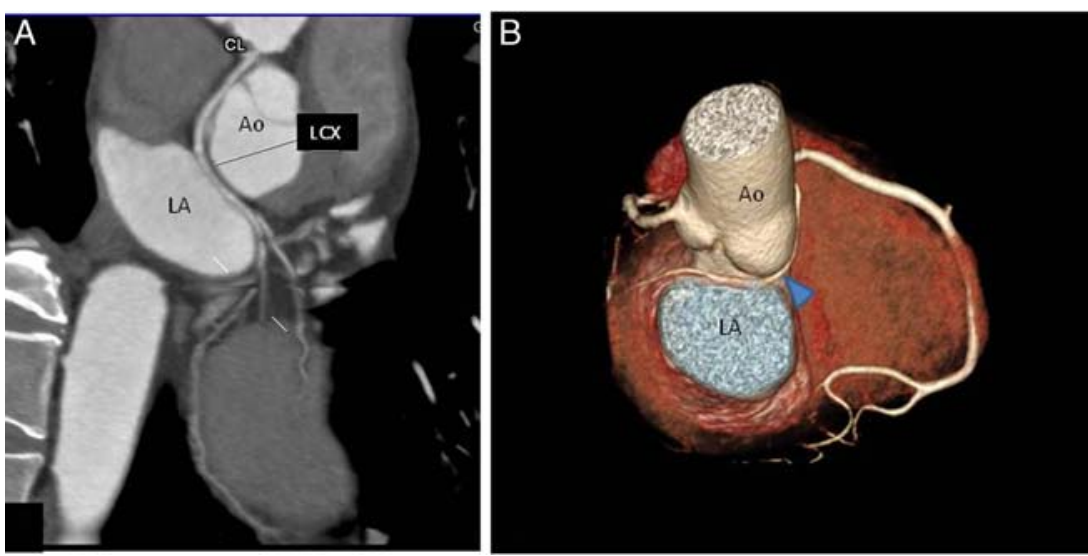

\section{Learning points}

- Most patients of congenitally absent left circumflex artery (LCX) are asymptomatic; however, they may develop symptoms due to transient ischaemia of other coronary arterial territories due to stealing of blood in LCX.

- An anomalous origin of LCX from right coronary sinus is the most common congenital variant and is divided into three types ${ }^{3}$ :

- Type I: Separate ostia for right coronary artery (RCA) and LCX.

- Type II: Common ostia in the right sinus.

- Type III: LCX arising as a branch of the proximal RCA.

- CT coronary angiography is an excellent non-invasive imaging modality for detection of coronary artery anomalies.
Competing interests None declared.

Patient consent Obtained.

Provenance and peer review Not commissioned; externally peer reviewed.

\section{REFERENCES}

1 Hongsakul K, Suwannanon R. Congenital absence of left circumflex artery detected by computed tomography coronary angiography: a case report. Case Rep Vasc Med 2012;2012:204657.

2 Mohsen GA, Mohsin KG, Forsberg M, et al. Anomalous left circumflex artery from the right coronary cusp: a benign variant? J Invasive Cardiol 2013;25:284-7.

3 Page HL, Engel HJ, Campbell WB, et al. Anomalous origin of the left circumflex coronary artery: recognition, angiographic demonstration and clinical significance. Circulation 1974;50(4):768-73.

Copyright 2015 BMJ Publishing Group. All rights reserved. For permission to reuse any of this content visit

http://group.bmj.com/group/rights-licensing/permissions.

BMJ Case Report Fellows may re-use this article for personal use and teaching without any further permission.

Become a Fellow of BMJ Case Reports today and you can:

- Submit as many cases as you like

- Enjoy fast sympathetic peer review and rapid publication of accepted articles

- Access all the published articles

- Re-use any of the published material for personal use and teaching without further permission

For information on Institutional Fellowships contact consortiasales@bmjgroup.com

Visit casereports.bmj.com for more articles like this and to become a Fellow 